\title{
Kesetaraan hula-hula dengan boru dalam budaya Batak Toba: Tinjauan sosio-teologis Galatia 3:28
}

\author{
Roy Martin Simanjuntak ${ }^{1 *}$, Niken Dewi Prananingtyas ${ }^{2}$, Marianus Pattora ${ }^{3}$, \\ Harry Soegijono ${ }^{4}$, Setya Hadi Nugroho ${ }^{5}$ \\ 1,2,3,4,5 Sekolah Tinggi Agama Kristen Teruna Bhakti, Yogyakarta \\ *Correspondence: elroysimanjuntak@gmail.com
}

https://orcid.org/00000003-0634-0797

Keywords:

Batak culture; Batak philosophy; boru; dalihan na tolu; equality;

Galatians 3:28;

hula-hula;

falsafah Batak;

Galatia 3:28;

kebudayaan Batak;

kesetaraan

\section{Article History}

Submitted: August 14, 2021

Revised: August 25, 2021

Accepted: October 01, 2021

DOI: https://doi.org/ 10.30995/kur.v7i2.354

Copyright: @2021, Authors.

License:

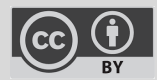

Scan this QR,

Read Online

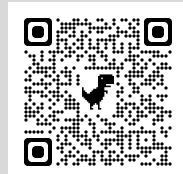

Abstract: Dalihan Na Tolu is a culture and philosophy of life of the Batak people. It is not only the kinship relationship contained in it but also as a driving force for the life order of the believers. In the Dalihan Na Tolu philosophy, there is a relationship that needs to be evaluated in relation to social equality, namely the relationship between Hula-hula and Boru. The perspective of Christian faith will complement the philosophy of Dalihan Na Tolu if it is built in the love and sacrifice of Christ, which is ultimately driven by love in the Dalihan Na Tolu philosophy. This study used a qualitative literature approach, which uses descriptive methods, and analysis-argumentative. descriptive, analysis-interpretive, and argumentation-comparative. With the constructive comparative aid method, this study uses various literature sources, such as books, journal articles, and dissemination on web pages to gain new insights from the text being studied. The conclusion that can be drawn is that the theology of social equality in the perspective of the Christian faith should complement the philosophy of Dalihan Na Tolu which centers on the love and sacrifice of Christ. The relationship between hula-hula and boru is no longer seen as an order of law that implies a curse but rather as local wisdom that enriches mission values to introduce the love of Christ through the Dalihan Na Tolu philosophy.

Abstrak: Dalihan Na Tolu adalah sebuah budaya dan falsafah hidup bagi orang Batak. Tidak hanya hubungan kekerabatan yang terkandung di dalamnya, tetapi juga sebagai penggerak tatanan kehidupan. Dalam falsafah Dalihan $\mathrm{Na}$ Tolu ada hubungan yang menarik untuk diperhatikan berkaitan kesetaraan sosial, yaitu hubungan antara Hula-hula dengan Boru. Hubungan ini sering dianggap sebagai bentuk kesenjangan sosial, sehingga dalam perkembangan zaman banyak orang Batak yang telah memiliki paradigma yang berubah terhadap falsafah Dalihan Na Tolu. Artikel ini mengkaji bahwa hubungan antara Hulahula dan Boru dalam falsafah Dalihan Na Tolu adalalah sebuah kesetaraan sosial dan tidak bertentangan dengan iman Kristen. Perspektif iman Kristen akan menjadi penyempurna falsafah Dalihan Na Tolu karena dalam penerapannya telah membangun falsafah tersebut dengan dasar kasih Kristus sebagai mana yang dituliskan Paulus dalam Galatia 3:28. Pemaknaan dari sisi konteks Galatia 3:28 memberikan korelasi yang jelas mengenai kesetaraan dalam falsafah Dalihan Na Tolu. Penelitian ini menggunakan metode kualitatif dan deskriptif. 


\section{Pendahuluan}

Budaya merupakan identitas suatu suku atau bangsa yang dapat menggambarkan dan sebagai representasi karakteristik dalam masyarakat untuk dikenal. Di sisi lain, budaya menjadi sebuah perdebatan dalam masyarakat jika dihubungkan dengan iman Kristen di masa sekarang. Sebagian orang Kristen beranggapan bahwa budaya tidak bertentangan dengan iman, tetapi ada juga sebagian kelompok orang Kristen yang beranggapan bahwa budaya sangat bertentangan dengan iman Kristen, sehingga mereka meninggalkan budaya atas nama iman. James A. Lola dalam tulisannya menyebutkan bahwa budaya dan manusia merupakan hubungan dua arah yang bersifat resiprokal yang dapat memberikan ketegangan-ketegangan di dalam masyarakat. ${ }^{1}$

Salah satu budaya yang menarik diselidiki adalah budaya Batak. Batak merupakan salah satu suku yang tinggal di Propinsi Sumatera Utara. Dalam menjaga kelestarian budaya, maka suku Batak sangat menjunjung tinggi nilai-nilai budaya sekalipun sudah berdiaspora. Bahkan, sistem kekerabatan orang batak bersifat Patrilineal2, yang diatur dalam falsafah "Dalihan Na Tolu". Falsafah ini sangat mempengaruhi kehidupan orang batak mulai dari kelahiran, perkawinan dan juga tata cara berhubungan sosial. ${ }^{3}$ Dalam falsafah Dalihan Na Tolu, hubungan antara hula-hula dan boru sangat menarik untuk diperhatikan, karena dari sisi penerapan dalam konteks adat dan kehidupan sehari-hari sepertinya pihak boru adalah posisi yang tidak diuntungkan. Sikap pihak boru terhadap hula-hula yang begitu hormat dan taat sampai terkesan tidak memiliki hak (sipangoloi). Selain itu, pihak hula-hula cenderung mempergunakan posisi sebagai hula-hula dalam mencapai keinginan pribadi. Misalnya, "Ikkon oloi on mu do hula-hulamu ai nasida do Debata na tarida", yang berarti kamu harus mengikuti keinginan hula-hulamu sebab mereka adalah Tuhan yang kelihatan. Hal-hal seperti ini tentu dapat disalah artikan dan akhirnya berimplikasi kepada banyak hal.

Sejalan dengan perkembangan zaman, masyarakat Batak juga mengalami pergeseran paradigma mengenai budaya dan adat istiadat, pergeseran ini dipengaruhi beberapa faktor, mulai dari faktor teknologi samapai faktor teologi. Tidak sedikit masyarakat Batak yang menganggap budaya dan adat istiadat telah ketinggalan zaman dan dianggap bertentangan dengan keyakinan sehingga budaya tersebut semakin lama akan menjadi terhilang termasuk falsafah Dalihan $\mathrm{Na}$ Tolu.

Penelitian-penelitian terhadap Dalihan Na Tolu telah dilakukan oleh peneliti sebelumnya, namun belum melihat dari sisi kesetaraan sosial. Megawati Manullang menjelaskan bahwa Dalihan Na Tolu merupakan sebuah kearifan lokal yang dapat dipakai sebagai jembatan untuk membangun kerukunan beragama sebagai bentuk pelayanan Misi. ${ }^{4}$ Seperti halnya juga Yohanes memakai konsep logos dalam memperkenalkan Yesus. ${ }^{5}$ Mohammad Novriansyah menyebutkan Dalihan Na Tolu dapat menjadi kontrol sosial dalam kemajuan teknologi. Fokus penelitiannya adalah para pelajar yang hidup bergantung dengan teknologi dan media sosial. ${ }^{6}$ Kondar Siregar menuliskan budaya masyarakat Dalihan Na Tolu dapat dijadikan sebagai pencegah tindakan amoral seperti prostitusi dan juga tindakan anarkis lainnya. Penanaman nilai-nilai Dalihan Na

\footnotetext{
1 James A Lola Sekolah, Tinggi Agama, and Kristen Negeri Toraja, "Iman Kristen Dan Budaya Popular," Visio Dei: Jurnal Teologi Kristen 1, no. 1 (June 27, 2019): 101-121, accessed November 18, 2021, http://jurnal.sttstarslub.ac.id/index.php/js/article/view/7.

${ }^{2}$ rut Debora Butarbutar, "Dalihan Na Tolu Sebagai Sistem Kekerabatan Batak Toba Dan Rekonstruksinya Berdasarkan Teologi Persahabatan Kekristenan," https://ejournal.unhi.ac.id/index.php/dharmasmrti/article/view/1019/650.

${ }^{3}$ Ibid.

${ }^{4}$ Megawati Manullang, Cultivation, Jurnal Teologi Cultivation, vol. 2, July 27, 2018, http://jurnal.stakpntarutung.ac.id/index.php/Jurnal-Teologi-Cultivation.

${ }^{5}$ Roy Martin Simanjuntak, "Kristologi Dalam Injil Yohanes," Jurnal Teruna Bhaktl 1, no. 2 (March 19, 2019): 75, accessed April 1, 2021, http://stakterunabhakti.ac.id/e-journal/index.php/teruna.

${ }^{6}$ Muhammad Novriansyah Lubis, "Dalihan Na Tolu Sebagai Kontrol Sosial Dalam Kemajuan Teknologi | Lubis | Sejarah Dan Budaya : Jurnal Sejarah, Budaya, Dan Pengajarannya," http://journal2.um.ac.id/index.php/sejarahdan-budaya/article/view/7575/3988.
} 
Tolu melalui pranata marga, pranata tutur dan penegakan hukum adat. ${ }^{7}$ Armaidy Armawi meneliti Dalihan Na Tolu dan Good Governance dalam birokrasi publik menjadi sebuah problematika. Dalam penelitiannya Armawi memberi penjelasan bahwa dalam menjalankan tugas dan fungsi dalam birokrasi secara tradisional masih mengedepankan hubungan marga, kedekatan kekerabatan sehingga menjadi penghalang dalam menjalankan sistem birokrasi yang baik. ${ }^{8}$ Anwar Sadat Harahap dalam penelitiannya menjadikan falsafah Dalihan Na Tolu sebagai sistem musyawarah dalam menyelesaikan sengketa perusakan hutan pada masyarakat. ${ }^{9}$

Dari beberapa penelitian falsafah Dalihan Na Tolu yang telah disebutkan di atas belum ada yang meneliti dari sisi kesetaraan sosial. Penulisan artikel ini bertujuan untuk menganalisis budaya Batak Toba dalam falsafah Dalihan Na Tolu dari perspektif kesetaraan Hula-hula dan boru sebagai tinjauan sosio teologis berdasarkan kitab Galatia 3:28 sehingga dapat memberikan pemahaman bagi masyarakat khususnya masyarakat Batak agar menjaga kelestarian budaya.

\section{METODE}

Artikel ini membahas kesetaraan sosial dalam falsafah Dalihan Na Tolu yang difokuskan pada pembahasan kesetaraan antara Hula-hula dan Boru dari perpspektif Galatia 3:28. Penelitian ini menggunakan pendekatan kualitatif dengan metode deskriptif. Subagyo menjelaskan pendekatan tatanan sosial yang dikaji akan menghasilkan sebuah penegasan bagi masyarakat sehingga dapat dipertahankan kelangsungannya. ${ }^{10}$ Sementara Moleong memberi penjelasan bahwa penelitian kualitatif adalah penelitian yang bermaksud memahami apa yang sedang dialami subjek misalnya perilaku, tindakan atau persepsi. ${ }^{11}$ Oleh karena penelitian ini memakai kacamata teks Galatia 3:28 maka diperlukan juga kajian hermeneutik. Pemakaian tinjauan hermeneutik adalah untuk memperoleh pemahaman mengenai makna dalam konteks sehingga dapat diterapkan di masa kini. ${ }^{12}$ Selain pendekatan deskriptif peneliti juga mengkaji berbagai literatur melalui artikel jurnal, buku dan diseminasi yang terdapat pada laman web yang berhubungan dengan topik pembahasan. Studi pustaka ini akan menjadi acuan dalam memberi kesimpulan.

\section{Pembahasan}

\section{Memaknai Dalihan Na Tolu}

\section{Mitologi Dalihan Na Tolu}

Falsafah Dalihan Na Tolu dimaknai dari sebuah pemahaman mitologi batak yaitu tungku, dimana tungku yang disusun dengan tiga bagian yang membentuk lingkaran ${ }^{13}$ atau disebut dengan tungku na tolu. Bagian ini kemudian dihubungkan dengan tolu banua (tiga benua), yaitu banua ginjang (benua atas/langit), banua tonga (benua tengah/bumi), dan banua toru (benua bawah) ${ }^{14}$ Keti-

\footnotetext{
${ }^{7}$ Kondar Siregar, "Pencegahan Tindak Prostitusi Berbasis Masyarakat Adat Dalihan Na Tolu | Siregar | Mimbar Hukum - Fakultas Hukum Universitas Gadjah Mada," https://journal.ugm.ac.id/jmh/article/view/16676/12151.

${ }^{8}$ Armaidy Armawi, "Kearifan Lokal Batak Toba Dalihan Na Tolu Dan Good Governance Dalam Birokrasi Publik," Jurnal Filsafat "Wisdom" 18, no. 2 (October 15, 2016): 157-166, accessed May 10, 2021, https://journal.ugm.ac.id/wisdom/article/view/3522.

${ }_{9}^{9}$ Anwar Sadat et al., Prosiding Seminar Nasional Hasil Penelitian, 2018, accessed May 10, 2021, http://geospasial.bnpb.go.id/pantauanbencana/data/datakbhutanall.php.

${ }^{10}$ Andreas B Subagyo, Pengantar Riset Kuantitatif Dan Kualitatif (Termasuk Riset Teologi Dan Keagamaan), 1st ed. (Bandung: Yayasan Kalam Hidup, 2004).

${ }^{11}$ L. Moleong, Metodologi Penelitian Kualitatif (Bandung: Remaja Karyaa, 2010).

${ }^{12}$ Subagyo, Pengantar Riset Kuantitatif Dan Kualitatif (Termasuk Riset Teologi Dan Keagamaan).

${ }^{13}$ Suhaimy Pasaribu, Etika Dalihan Natolu Dalam Masyarakat Batak Muslim, n.d., accessed March 31, 2021, https://repository.uinjkt.ac.id/dspace/handle/123456789/53556.

${ }^{14}$ Risalan Basri Harahap, Analisis Kritis Peran Dalihan Natolu Dalam Perkawinan Masyarakat Batak Angkola Tapanuli Selatan, Jurnal AL-MAQASID: Jurnal IImu Kesyariahan Dan Keperdataan, vol. 5, 2019, accessed March 31, 2021, http://jurnal.iain-padangsidimpuan.ac.id/index.php/almaqasid/article/view/1718.
} 
ga benua (tolu banua) adalah ciptaan Debata Namulajadi Na Bolon. ${ }^{15}$ Tiga ide tersebut disebutkan sebagai Dalihan Na Tolu yang isinya adalah Dongan Tubu (satu marga), Hula-hula (marga dari pihak istri, tetapi yang laki-laki), dan Boru (marga yang sama dengan istri, tetapi perempuan) dan falsafhnya adalah Somba Marhulahula, Elek Marboru, Manat Mardongan Tubu. ${ }^{16}$ Jika diartikan maka menjadi: Rasa hormat/sembah kepada pihak marga istri tetapi yang laki-laki, pintarlah mengambil hati kepada marga istri yang perempuan dan hati-hatilah kepada yang satu marga antara yang laki-laki. Dalam tiga falsafah tersbutlah tersusun semua praktek hidup orang batak ${ }^{17}$, dan berlaku dalam semua aspek.

\section{Peran dan Fungsi dalam Dalihan Na Tolu}

Sebagai mana disebutkan di atas perihal Dalihan Na Tolu, maka peran dan fungsi masing-masing (Hula-hula, Boru, Dongan Tubu) akan terlihat jelas tidak saja berhubungan dengan acara adat, tetapi juga dalam hubungan sosial setiap hari. Hula-hula adalah yang paling dihormati, bahkan dianggap Debata Na Tarida (Tuhan yang kelihatan), yang mampu menyalurkan berkat. ${ }^{18}$ Posisi ini sangat dianggap sebagai yang superior sehingga memanggil namanya sajapun dianggap tokka (pantangan). Dalam proses acara adat, maka posisi Hula-hula ditempatkan di tempat terhormat, dan ketika manortor pihak boru akan menundukkan diri sebagai mana layaknya Tuhan yang disembah yang menjadi sumber kehidupan. ${ }^{19}$ Dalam acara adat secara formal, pihak hula-hula memiliki peran penting dalam sebuah acara, bukan saja dalam prosesinya tetapi juga sebagai pihak yang ditunggu kehadirannya dalam memulainya sebuah acara. Biasanya pihat tuan rumah (suhut) jika ingin memulai acara akan bertanya kepada raja parhata (juru bicara) apakah hulahula sudah ada di tempat supaya acara dimulai.

Dalam acara adat, boru adalah kelompok yang paling rendah, yang disebut hatoban, parhobas, siloja-loja (bagian yang mengerjakan dalam acara). Tidak ada alasan menolak jika diperintah oleh pihak hula-hula, dan jawabnya hanya "sipangoloi do Hami Raja nami" (kami hanya taat untuk bekerja). ${ }^{20}$ Tidak sekadar tenaga yang dikorbankan, melainkan juga finansial. Pihak boru akan rela melakukan upaya apa saja termasuk berhutang demi mangolopi (ketundukan) hulahulanya. Penundukan pihak boru terhadap pihak hula-hula adalah sebagai bentuk simbolis rasa hormat dan ketaatan dalam menunjukkan sikap kesetiaannya. ${ }^{21}$ Dalam hal ini, posisi boru dalam falasafah dalihan na tolu dapat dikatakan sebagai pihak yang imperior karena dalam perannya hanya sebagai pelaksana dan tidak memiliki hak.

Dongan Tubu adalah yang sesama marga, yang dalam hal ini adalah posisi yang paling netral dalam Dalihan Na Tolu. ${ }^{22}$ Saling menghormati sesama marga (marsipasangapan). Tidak

15 Ibid.

${ }^{16}$ Desniati Harahap and Implikasi Sistem Kekerabatan, Implikasi Sistem Kekerabatan Dalihan Na Tolu (Studi Pada Keluarga Urban Muslim Batak Angkola Di Yogyakarta), Ejournal.Unhi.Ac.ld, n.d., accessed March 27, 2021, https://ejournal.unhi.ac.id/index.php/dharmasmrti/article/view/1019.

${ }^{17}$ Edison Adrian Sihombing, "View of Mengenal Budaya Batak Toba Melalui Falsafah 'Dalihan Na Tolu' (Perspektif Kohesi Dan Kerukunan)," accessed March 31, 2021, https://jlka.kemenag.go.id/index.php/lektur/article/view/553/374.

${ }^{18}$ Ruth Nauli Aninda, "Nilai Anak Perempuan Pada Keluarga Batak Ditinjau Dari Ibu Dewasa Awal Dan Dewasa Madya," CALYPTRA 2, no. 1 (March 1, 2013): 1-13, accessed March 31, 2021, http://journal.ubaya.ac.id/index.php/jimus/article/view/394.

${ }^{19}$ Megawati Manullang, Cultivation, E-Journal.lakntarutung.Ac.Id, vol. 2, 2018, accessed March 27, 2021 , http://jurnal.stakpntarutung.ac.id/index.php/Jurnal-Teologi-Cultivation.

${ }^{20}$ Siti Maryam Pane, "Pengaruh Dalihan Na Tolu Dalam Masyarakat," jurnal.ugn.ac.id 4, no. 1 (2019), https://jurnal.ugn.ac.id/index.php/ESTUPRO/article/view/450.

${ }^{21}$ Masda Surti Simatupang, Ramot Peter, and Erni Murniarti, The Kinship Of "Dalihan Na Tolu" Of Batak Culture In Indonesia-Palarch's, Journal Of Archaeology Of Egypt/Egyptology, vol. 17, n.d., accessed May 10, 2021, https://archives.palarch.nl/index.php/jae/article/download/1764/1753.

${ }^{22}$ Butarbutar, "Dalihan Na Tolu Sebagai Sistem Kekerabatan Batak Toba Dan Rekonstruksinya Berdasarkan Teologi Persahabatan Kekristenan." 
terlalu banyak tanggung jawabnya apalagi dalam relasi sosialnya, hanya dikatakan elek marboru (membujuk, ambil hati).

\section{Kesetaraan Hulahula dan Boru dalam Dalihan Na Tolu}

Peran dan fungsi dalam falsafah Dalihan Na Tolu yang telah diuraikan di atas, memberi kesan adanya kesenjangan antara Hula-hula dengan Boru. Hula-hula digambarkan sebagai pihak yang superior sedangkan pihak Boru digambarkan sebagai pihak yang imperior, sama seperti antara tuan dan hamba. ${ }^{23} \mathrm{Hula}$-hula mutlak harus dihormati oleh boru, sebab akan mendatangkan kutuk jika tidak menghormati hula-hula, seperti serat rejeki, bahkan tidak mempunya keturunan. ${ }^{24}$ Memang, problem yang sering terjadi pada fungsi masing-masing dalam Dalihan Na Tolu yang dijelaskan di atas adalah bahwa pihak hulahula cenderung sering terjebak dalam kekeliruan saat melaksanakan fungsinya baik dalam acara adat formal atau secara nonformal dalam membangun interaksi sosial dengan pihak boru. Misalnya, pihak boru tidak diijinkan berbicara secara bebas atau interupsi pada saat acara adat (ulaon); bahkan, pihak boru tidak boleh memberikan nasihat kepada pihak Hula-hula karena dianggap tidak sopan. Hal seperti ini akan membawa pengaruh dalam konteks pelayanan dalam gereja. Terlebih lagi, pihak Hula-hula masih banyak yang menjadikan posisinya untuk mencari kepentingan pribadi atas nama Dalihan Na Tolu.

Pada prinsipnya, kesetaraan antara hula-hula dan boru dalam falsafah Dalihan Na Tolu merupakan kesetaraan dalam kekerabatan keluarga. Artinya, keberlangsungan hubungan ini lebih kepada ikatan keluarga yang mempunyai pandangan dan tradisi tersendiri. Risalan Basri Harahap menyebutkan bahwa hubungan sosial dalam Dalihan Na Tolu adalah suatu hubungan kekerabatan yang tidak dapat dipandang sebagai kesenjangan sosial. Sebab, sekalipun pihak hula-hula sebagai pihak teratas, namun di sisi yang lain, pihak hula-hula juga memiliki tanggung jawab untuk mengasihi pihak boru. ${ }^{25}$

Jika dalam kasus tertentu pihak hula-hula terjebak dalam penyalahgunaan fungsi dan cenderung memanfaatkan budaya Dalihan Na Tolu demi mencari kepentingan pribadi, hal tersebut merupakan sebuah kasus yang seharusnya tidaklah demikian, dan tidak dapat dijadikan sebagai alasan untuk meninggalkan budaya. Selain itu, posisi sebagai hula-hula, boru, dan dongan tubu dalam falsafah Dalihan Na Tolu sifatnya akan bergeser sesuai acara dan adat yang akan dilakukan. Hal ini berarti, tidak selamanya pihak hulahula berfungsi sebagai hulahula dalam acara adat karena hulahula dalam konteks tertentu bisa berubah fungsi sebagai boru dalam acara dan konteks yang lain.

\section{Tinjauan Kesetaraan dalam Galatia 3:28}

\section{Memaknai Galatia 3:28}

Topik utama Paulus dalam bagian ini adalah, sedang menjelaskan makna kemerdekaan Kristen. Orang Kristen Galatia telah membuang kemerdekaan mereka dengan kembali kepada tuntutan perbudakan Hukum Taurat. ${ }^{26}$ Dalam teks Galatia 3:28 menyebutkan "Tidak ada orang Yahudi atau orang Yunani, tidak ada hamba atau orang merdeka, tidak ada laki-laki atau perempuan, karena kamu semua ada di dalam Kristus Yesus." Bagian ini sangat jelas menggambarkan kesetaraan gender dan kesetaraan sosial. Kata eni merupakan bentuk kala kini aktif indikatif yang berarti

\footnotetext{
${ }^{23}$ Maryam Pane, "Pengaruh Dalihan Na Tolu Dalam Masyarakat."

${ }^{24}$ Harahap, Analisis Kritis Peran Dalihan Natolu Dalam Perkawinan Masyarakat Batak Angkola Tapanuli Selatan, vol. 5, p. .

${ }^{25}$ Risalan Basri Harap, Analisis Kritis Peran Dalihan Natolu Dalam Perkawinan Masyarakat Batak Angkola Tapanuli Selatan, Jurnal AL-MAQASID: Jurnal IImu Kesyariahan Dan Keperdataan Fakultas Syariah Dan Ilmu Hukum IAIN Padangsidempuan, vol. 5, 2019, accessed March 31, 2021, http://jurnal.iainpadangsidimpuan.ac.id/index.php/almaqasid/article/view/1718.

${ }^{26}$ Tim Penyusun. Handbook to the Bible. Pedoman Lengkap Pendalaman Alkitab. (Bandung: Kalam Hidup, 2004), 679.
} 
sedang berlangsung ${ }^{27}$, sementara kata ouk berarti bukan/tidak, yang dihubungkan dengan noun, sehingga, dalam konteks ini, dipahami bahwa Paulus sedang menjelaskan mengenai posisi jemaat Galatia yang bukan "sedang (sebagai) seorang Yahudi/non-Yahudi, bukan sedang sebagai merdeka/hamba, bukan sedang sebagai laki-laki/perempuan". Sedangkan Yesus Kristus adalah penyebab kesatuan/kesetaraan yang dimaksud oleh Paulus. ${ }^{28}$

I. Howard Marshall menyebutkan, kedudukan jemaat Galatia setelah bersama Kristus adalah kehidupan yang baru sebagai anak Allah, dan bukan lagi diikat oleh hukum Taurat. ${ }^{29}$ Dalam konteks surat Paulus kepada jemaat di Galatia, secara umum menggambarkan kemerdekaan orang percaya di Galatia, sehingga tidak ada lagi perbedaan di antara jemaat. Hal ini penting diinformasikan sehubungan dengan adanya pengajar-pengajar palsu yang mencoba memengaruhi jemaat untuk kembali kepada Yudaisme. Dalam hal ini Paulus memberikan penegasan kepada jemaat Galatia bahwa iman di dalam Yesus Kristus adalah berdasarkan janji dan bukan hukum Taurat sehingga memiliki kemerdekaan.

\section{Kesetaraan Dalam Yesus Kristus}

Asnat Natar menyebutkan, bahwa melalui pengorbanan-Nya di salib, Yesus Kristus telah menghancurkan semua perbedaan, baik perbedaan sosial dan perbedaan gender, karena telah mendapat pembenaran dalam Kristus. ${ }^{30}$ Konsep kesetaraan bagi orang percaya di dalam Yesus memungkinkan setiap orang percaya mendapat kedudukan yang sama dan memiliki kesempatan untuk menjadi pemimpin. ${ }^{31}$ Bahkan penderitaan Yesus di kayu salib adalah wujud solidaritas Allah kepada manusia sebagai gambaran kesetaraan. ${ }^{32}$ Pelayanan Yesus kepada orang miskin, perempuan sundal adalah sebuah teladan dan bukti bahwa Yesus selalu memposisikan diriNya setara dengan seseorang sekalipun di sisi yang berbeda Yesus sebagai Tuhan. Fritz Rienecker menyebutkan bahwa keselamatan adalah sebuah kebebasan ${ }^{33}$ hal inilah yang dimaksudkan kesetaraan di dalam Yesus Kristus. ${ }^{34}$

Di dalam Keristenan tidak lagi terdapat kelompok superior dan imperior, karena Yesus adalah kepala, dan orang percaya sebagai tubuh yang mempunyai kedudukan yang sama sekalipun dalam fungsi yang berbeda. Kedudukan dan fungsi orang percaya di dalam gereja adalah untuk membangun Tubuh Kristus. Bangsa-bangsa yang bukan Yahudi dipanggil sebagai pewaris dan mengambil bagian dalam tubuh Kristus. Hal ini berimplikasi kepada kedudukan dan statusnya yang dahulu jauh sekarang menjadi dekat. Ini adalah rahasia ilahi. ${ }^{35}$

\section{Korelasi Kesetaraan Sosial dengan Falsafah Dalihan Na Tolu}

Hubungan antara hula-hula dengan boru dalam falsafah Dalihan Na Tolu memerlukan sikap hormat, patuh, dan tunduk dari pihak boru kepada pihak hula-hula, yang terkesan menimbulkan kesenjangan. Secara umum, dalam pandangan masyarakat, bahwa proses kekerabatan tersebut terlihat adanya antara superior dan imperior, dalam hal ini relasi pihak boru dan hula-hula. Nilai

\footnotetext{
${ }^{27}$ Hasan Sutanto, Perjanjian Baru Interlinear dan Konkordansi. (Jakarta: Lembaga Alkitab Indonesia, 2004), 1013.

${ }^{28} \mathrm{Ibid}$.

${ }^{29}$ I. Howard Marshall, New Testament Theology (Downers Grove, Illinois: InterVarsity Press, 2004).

${ }^{30}$ Asnath Natar, "Paulus Dan Perempuan Suatu Kajian Terhadap 1 Korintus 14:33B-36 | Gema Teologi," http://journal-theo.ukdw.ac.id/index.php/gema/article/view/145.

${ }^{31}$ Johannis Siahaya Sekolah Tinggi Agama Kristen Teruna Bhakti, Kepemimpinan Kristen Dalam Pluralitas Indonesia, JURNAL TERUNA BHAKTI, vol. 1, March 18, 2019, http://stakterunabhakti.ac.id/ejournal/index.php/teruna.

${ }^{32}$ Sonny Eli Zaluchu, "Penderitaan Kristus Sebagai Wujud Solidaritas Allah Kepada Manusia | Zaluchu | DUNAMIS: Jurnal Teologi Dan Pendidikan Kristiani," https://www.sttintheos.ac.id/ejournal/index.php/dunamis/article/view/129/114.

${ }^{33}$ Fritz Rienecker. A Linguistic Key To The Greek New Testament. (Michingan: Grand Rapids, 1980), 510.

${ }^{34}$ Yehuda Mandacan, Kesetaraan Pria Dan Wanita (Gender) Menurut Alkitab, LOGON ZOES: Jurnal Teologi, Sosial Dan Budaya, vol. 2, 2018, https:/e-journal.stteriksontritt.ac.id/index.php/logon/article/view/11.

${ }^{35}$ Kecin J. Conner, Jemaat Dalam Perjanjian Baru (Malang: Gandum Mas, 2004).
} 
ketaatan dan sikap hormat pihak boru kepada hula-hula merupakan sikap yang sangat baik, dan di dalamnya terkandung nilai-nilai iman Kristen. Falsafah Dalihan Na Tolu begitu penting dalam masyarakat Batak, karena selain nilai moral, juga terdapat nilai teologis yang terkandung di dalamnya. Pihak boru yang kelihatannya sebagai pihak yang dirugikan, namun secara teologis sebagai simbol dari Allah yang melayani. ${ }^{36}$ Secara teologis, dalam Galatia 3:28, telah memberikan gambaran kehidupan orang percaya yang memiliki kemerdekaan sosial, gender, dan suku melalui pengorbanan Kristus. Paulus sendiri menganggap proses itu adalah sebuah misteri Allah. ${ }^{37}$

Dalam menjalankan tugas dan fungsinya, falsafah Dalihan Na Tolu secara tidak langsung telah menerapkan nilai-nilai Kristen walaupun dalam situasi yang terkondisikan. Artinya, masyarakat Batak telah mengambil bagian dalam menciptakan keharmonisan dalam masyarakat melalui falsafah Dalihan Na Tolu; konsep ini adalah bagian dari kehidupan bergereja. Masyarakat Batak, yang telah percaya kepada Kristus, dalam menjalankan falsafah Dalihan Na Tolu tidak lagi berpusat kepada dirinya sebagai pihak hula-hula atau boru, melainkan berpusat kepada Kristus dalam menjalan tugas dan fungsinya. Sehingga, dalam hal ini pihak boru dalam menghormati hula-hula tidak lagi dibangun dengan alasan tidak diberkati atau takut terkutuk. Sama seperti orang Galatia yang memahami arti pemuliaan terletak dalam pengorbanan Yesus, bukan lagi dalam tuntutan hukum taurat yang memberikan implikasi rasa takut dalam menjalankannya. ${ }^{38}$

\section{KESIMPULAN}

Hubungan antara hula-hula dengan boru dalam falsafah Dalihan Na Tolu bukanlah sebagai bentuk kesenjangan sosial, melainkan sebagai fungsi yang juga dapat berubah-ubah sesuai adat dan konteks tertentu. Falsafah Dalihan Na Tolu sebenarnya telah mengandung nilai-nilai iman Kristen, dalam hal ketaatan dan harmoni dalam keluarga, yang saling menghormati dan mengasihi. Sehubungan dengan terjadinya pemahaman yang keliru mengenai falsafah Dalihan Na Tolu maka artikel ini memberi kesimpulan, bahwa hubungan antara Hula-hula dan Boru merupakan sebuah kesetaraan yang dapat dibenarkan dari sisi Alkitab, sehingga masyarakat Batak tetap melestarikannya sebagaimana mestinya. Falsafah ini telah memberikan sebuah nilai-nilai iman terutama bagi masyarakat Batak yang telah percaya kepada Yesus Kristus, sehingga dalam menjalankan tugas dan fungsi dalam falsafah Dalihan Na Tolu tidak lagi membangun pemahaman karena takut terhadap kutuk, melainkan karena kasih Kristus.

\section{REFERENSI}

Aninda, Ruth Nauli. "Nilai Anak Perempuan Pada Keluarga Batak Ditinjau Dari Ibu Dewasa Awal Dan Dewasa Madya." CALYPTRA 2, no. 1 (March 1, 2013): 1-13. Accessed March

31, 2021. http://journal.ubaya.ac.id/index.php/jimus/article/view/394.

Armawi, Armaidy. "Kearifan Lokal Batak Toba Dalihan Na Tolu Dan Good Governance Dalam

Birokrasi Publik." Jurnal Filsafat "Wisdom" 18, no. 2 (October 15, 2016): 157-166.

Accessed May 10, 2021. https://journal.ugm.ac.id/wisdom/article/view/3522.

Butarbutar, Rut Debora. "View of Dalihan Na Tolu Sebagai Sistem Kekerabatan Batak Toba

Dan Rekonstruksinya Berdasarkan Teologi Persahabatan Kekristenan." Accessed March

31, 2021. https://ejournal.unhi.ac.id/index.php/dharmasmrti/article/view/1019/650.

Conner, Kecin J. Jemaat Dalam Perjanjian Baru. Malang: Gandum Mas, 2004.

\footnotetext{
${ }^{36}$ Adison Adrian Sihombing, "Mengenal Budaya Batak Toba Melalui Falsafah 'Dalihan Na Tolu' (Perspektif Kohesi Dan Kerukunan)," Jurnal Lektur Keagamaan 16, no. 2 (December 31, 2018): 347-371, accessed May 10, 2021, http://dx.doi.org/10.31291/jlk.v16i2.553.

${ }^{37}$ Mira Marleni Pandie et al., Misteri Allah Dalam Pandangan Paulus Dan Implikasinya Bagi Pemberitaan Masa Kinl, Jurnal Jaffray, vol. 10, October 1, 2012, https://www.ojs.sttjaffray.ac.id/JJV71/article/view/59.

${ }^{38}$ Tri Hartono, "Pembelaan Rasul Paulus Terhadap Konsep Yudaisme Mengenai Hukum Taurat Menurut Surat Galatia 1-5" KONSEP YUDAISME, Jurnal Salvation, vol. 1, 2019, accessed March 31, 2021, https://sttbkpalu.ac.id/jurnal/index.php/Salvation/article/view/18.
} 
Edison Adrian Sihombing. "View of Mengenal Budaya Batak Toba Melalui Falsafah 'Dalihan Na Tolu' (Perspektif Kohesi Dan Kerukunan)." Accessed March 31, 2021. https://jlka.kemenag.go.id/index.php/lektur/article/view/553/374.

Harahap, Desniati, and Implikasi Sistem Kekerabatan. Implikasi Sistem Kekerabatan Dalihan Na Tolu (Studi Pada Keluarga Urban Muslim Batak Angkola Di Yogyakarta). Ejournal.Unhi.Ac.Id, n.d. Accessed March 27, 2021. https://ejournal.unhi.ac.id/index.php/dharmasmrti/article/view/1019.

Harahap, Risalan Basri. Analisis Kritis Peran Dalihan Natolu Dalam Perkawinan Masyarakat Batak Angkola Tapanuli Selatan. Jurnal AL-MAQASID: Jurnal IImu Kesyariahan Dan Keperdataan. Vol. 5, 2019. Accessed March 31, 2021. http://jurnal.iainpadangsidimpuan.ac.id/index.php/almaqasid/article/view/1718.

Harap, Risalan Basri. Analisis Kritis Peran Dalihan Natolu Dalam Perkawinan Masyarakat Batak Angkola Tapanuli Selatan. Jurnal AL-MAQASID: Jurnal IImu Kesyariahan Dan Keperdataan Fakultas Syariah Dan Ilmu Hukum IAIN Padangsidempuan. Vol. 5, 2019. Accessed March 31, 2021. http://jurnal.iain-padangsidimpuan.ac.id/index.php/almaqasid/article/view/1718.

Hartono, Tri. "Pembelaan Rasul Paulus Terhadap Konsep Yudaisme Mengenai Hukum Taurat Menurut Surat Galatia 1-5" Konsep Yudaisme. Jurnal Salvation. Vol. 1, 2019. Accessed March 31, 2021. https://sttbkpalu.ac.id/jurnal/index.php/Salvation/article/view/18.

Kondar Siregar. "Pencegahan Tindak Prostitusi Berbasis Masyarakat Adat Dalihan Na Tolu | Siregar | Mimbar Hukum - Fakultas Hukum Universitas Gadjah Mada." Accessed March 31, 2021. https://journal.ugm.ac.id/jmh/article/view/16676/12151.

L. Moleong. Metodologi Penelitian Kualitatif. Bandung: Remaja Karyaa, 2010.

Manullang, Megawati. Cultivation. E-Journal.lakntarutung.Ac.Id. Vol. 2, 2018. Accessed March 27, 2021. http://jurnal.stakpntarutung.ac.id/index.php/Jurnal-Teologi-Cultivation.

- Cultivation. Jurnal Teologi Cultivation. Vol. 2, July 27, 2018. Accessed March 30, 2021. http://jurnal.stakpntarutung.ac.id/index.php/Jurnal-Teologi-Cultivation.

Marleni Pandie, Mira, Kata kunci, Misteri Allah, Pandangan Paulus, dan Pemberitaan Masa Kini, and Mahasiswa Program Pascasarjana yang mengambil Mata Kuliah Teologi Perjanjian Baru. Misteri Allah Dalam Pandangan Paulus Dan Implikasinya Bagi Pemberitaan Masa Kini. Jurnal Jaffray. Vol. 10, October 1, 2012. Accessed March 31, 2021. https://www.ojs.sttjaffray.ac.id/JJV71/article/view/59.

Marshall, I. Howard. New Testament Theology. Downers Grove, Illinois: InterVarsity Press, 2004.

Maryam Pane, Siti. "Pengaruh Dalihan Na Tolu Dalam Masyarakat." jurnal.ugn.ac.id 4, no. 1 (2019). Accessed March 27, 2021. https://jurnal.ugn.ac.id/index.php/ESTUPRO/article/view/450.

Muhammad Novriansyah Lubis. "Dalihan Na Tolu Sebagai Kontrol Sosial Dalam Kemajuan Teknologi | Lubis | Sejarah Dan Budaya : Jurnal Sejarah, Budaya, Dan Pengajarannya." Accessed March 31, 2021. http://journal2.um.ac.id/index.php/sejarah-danbudaya/article/view/7575/3988.

Natar, Asnath. "Paulus Dan Perempuan: Suatu Kajian Terhadap 1 Korintus 14:33B-36 | Gema Teologi." Accessed March 31, 2021. http://journaltheo.ukdw.ac.id/index.php/gema/article/view/145.

Pasaribu, Suhaimy. Etika Dalihan Natolu Dalam Masyarakat Batak Muslim, n.d. Accessed March 31, 2021. https://repository.uinjkt.ac.id/dspace/handle/123456789/53556.

Sadat, Anwar, Harahap Universitas Muslim, Nusantara Al, and Washliyah Abstrak. Prosiding Seminar Nasional Hasil Penelitian, 2018. Accessed May 10, 2021. http://geospasial.bnpb.go.id/pantauanbencana/data/datakbhutanall.php.

James A Lola, Tinggi Agama, and Kristen Negeri Toraja. "Iman Kristen Dan Budaya Popular." VISIO DEI: JURNAL TEOLOGI KRISTEN 1, no. 1 (June 27, 2019): 101-121. Accessed November 18, 2021. http://jurnal.sttstarslub.ac.id/index.php/js/article/view/7. 
Siahaya Sekolah Tinggi Agama Kristen Teruna Bhakti, Johannis. Kepemimpinan Kristen Dalam Pluralitas Indonesia. JURNAL TERUNA BHAKTI. Vol. 1, March 18, 2019. Accessed April 1, 2021. http://stakterunabhakti.ac.id/e-journal/index.php/teruna.

Sihombing, Adison Adrian. "Mengenal Budaya Batak Toba Melalui Falsafah 'Dalihan Na Tolu' (Perspektif Kohesi Dan Kerukunan)." Jurnal Lektur Keagamaan 16, no. 2 (December 31, 2018): 347-371. Accessed May 10, 2021. http://dx.doi.org/10.31291/jlk.v16i2.553.

Simanjuntak, Roy Martin. "Kristologi Dalam Injil Yohanes." JURNAL TERUNA BHAKTI 1, no. 2 (March 19, 2019): 75. Accessed April 1, 2021. http://stakterunabhakti.ac.id/ejournal/index.php/teruna.

Subagyo, Andreas B. Pengantar Riset Kuantitatif Dan Kualitatif (Termasuk Riset Teologi Dan Keagamaan). 1st ed. Bandung: Yayasan Kalam Hidup, 2004.

Surti Simatupang, Masda, Ramot Peter, and Erni Murniarti. The Kinship Of "Dalihan Na Tolu" Of Batak Culture In Indonesia-Palarch's. Journal Of Archaeology Of Egypt/Egyptology. Vol. 17, n.d. Accessed May 10, 2021. https://archives.palarch.nl/index.php/jae/article/download/1764/1753.

Yehuda Mandacan, Pdt, and MTh Pembantu Ketua III Bidang Kemahasiswaan. Kesetaraan Pria Dan Wanita (Gender) Menurut Alkitab. LOGON ZOES: Jurnal Teologi, Sosial Dan Budaya. Vol. 2, 2018. Accessed March 31, 2021. https://ejournal.stteriksontritt.ac.id/index.php/logon/article/view/11.

Zaluchu, Sonny Eli. "Penderitaan Kristus Sebagai Wujud Solidaritas Allah Kepada Manusia | Zaluchu | DUNAMIS: Jurnal Teologi Dan Pendidikan Kristiani." Accessed April 1, 2021. https://www.sttintheos.ac.id/e-journal/index.php/dunamis/article/view/129/114. 